\title{
Research on improving the employment ability of electric information specialty application talents under the cooperation between school and enterprise
}

\author{
Chang Shu \\ Technical School, Harbin University, Harbin, 150080 P.R. China \\ sum157@163.com
}

\begin{abstract}
With the incensement of the electric and information undergraduates in recent years, the pressure of the undergraduates' employment is increasing. In order to meet the needs of society, the electric information specialty training mode for local undergraduate colleges locate to the application talents training gradually. Therefore, how to improve these application talents' employment ability has become an urgent problem to be solved. To improve the employment ability of application talents in electric information specialty, the cooperation between school and enterprise require further deepened based on the existing mode, and an effective training mode for applied talents needs to draft according to demands of present employer and problems students faced. Solving these problems will be success factor of training model reform for applied electrical specialty in the new situation.
\end{abstract}

Keywords: cooperation between school and enterprise; employment ability; applied undergraduate; specialty of electric and information paper.

\section{校企合作模式下提升电气信息类应用型人才就业能力的研究}

\author{
舒昌 \\ 1. 哈尔滨学院工学院, 哈尔滨, 黑龙江, 中国
}

摘 要: 随着近年来电气信息类本科生的增多, 致使该类本科生就业压力逐渐增大。为适应社 会需求, 地方本科院校电气信息类专业逐步将培养定位转向应用型人才培养。因此, 如何提 升电气信息类应用型人才的就业能力已成为亟待解决的问题。在现有校企合作模式的基础上, 针对目前用人单位对电气信息类应用型人才的需求以及学生就业面临的问题, 深化校企合作、 制定更为有效的应用型人才培养模式进而达到提升电气信息类应用型人才的就业能力是新形 势下应用型电气信息类专业人才培养模式改革能否成功的关键因素。

关键词：校企合作；就业能力；应用型本科；电气类专业

\section{1. 前言}

目前, 我国应届毕业生人数已达到 700 万左右, 大学毕业生的就业形势非常严峻。在如此严 峻的就业形势下, 如何有效地提高大学生的就业能力、增强大学生毕业后在就业市场的竞争 力是高校面临的重大考验, 同时也是全社会关注的热点问题 ${ }^{[1]}$ 。近年来, 随着我国高等教育 的大众化进程和大学生就业压力的不断增大, 出现了以应用型人才培养为突出特征的应用型 本科院校。为了适应社会需求, 地方本科院校的电气信息类专业也逐步将培养定位转向为应 用型人才培养。电气信息类专业应用型人才的就业能力是反映专业办学质量的重要指标, 也 是当前形势下应用型电气信息类专业谋求发展亟待解决的问题。校企合作是一种由学校和用 人单位合作共同培养学生的教育模式, 是提高大学生就业能力的有效途径之一 ${ }^{[2]}$, 在现有的 校企合作模式基础上, 针对目前用人单位对电气信息类应用型人才的需求及学生就业面临的 问题，探讨如何进一步深化校企合作、制定更为有效的应用型人才培养模式，进而达到提升 电气信息类应用型人才的就业能力是非常有意义的。 


\section{2. 应用型电气类专业学生就业能力的内涵}

\section{1. 大学生就业能力的内涵}

大学生就业能力是大学生将在校期间学习的知识和经验转化为快速适应和完全胜任工作岗位 的能力。它是一种与个人和社会环境等相关的综合能力, 包括基础能力、专业能力、实践能 力、学习能力和心理素质等几大方面, 它是一种以各方面为相互依托的素质群 ${ }^{[3]}$ 。

2.2. 应用型本科的定位及意义

随着教育改革的深化, 中国的高等教育已进入分层次、多元化的发展阶段。目前, 本科教育 的主要形式可分为研究型大学、教学研究型大学、教学应用型大学 ${ }^{[4]}$ 。其中, 应用型本科的 办学理念定位在培养应用型人才, 目的是为了满足中国经济社会发展对高层次应用型人才的 需要。它是以培养知识、能力和素质的全方面协调发展, 以面向一线生产、建设、管理、服 务的高级应用型人才培养为目标定位的高等教育。以就业和社会需求为导向, 应用型大学加 强人才培养的针对性, 通过加强基层一线岗位所需要的能力和素质的培养来满足技术人才市 场和生产需求, 这是应用型本科院校基本的办学特征和人才培养的类型特色。

2.3. 电气信息类应用型人才就业能力的要求

按照教育部颁发的专业目录分类和培养定位, 电气信息类专业涵盖电气工程及其自动化、自 动化、电子信息工程、通信工程、计算机科学与技术、电子科学与技术和生物医学工程 等专业。电气信息类专业的培养目标旨在培养适应社会信息化需求的具备应用电工电子技术 和信息系统等基础知识的从事与电子设备和信息系统相关的研究、设计、制造、应用、开发 和维护等工作的宽口径 “复合型” 高级工程技术人才。随着当前科学技术的迅猛发展, 电气 信息类应用型人才不仅要具备扎实的专业知识, 同时还要具备快速适应工作岗位的工程实践 能力、技术应用能力和创新实践能力。其中, 工程实践能力是毕业生必备的重要技能, 也是 培养本科生创新能力的基础 ${ }^{[5]}$ 。

\section{3. 当前应用型电气信息类专业学生就业能力存在的问题}

《国家中长期教育改革和发展规划纲要（2010-2020 年)》中要求: “高等教育应优化结构, 办出特色” ; 《国家教育事业发展第十二个五年规划》中强调： “对于高等教育规划的重点 是扩大应用型、技能型、复合型人才培养规模” 。因此新建地方本科院校在办学中应始终坚 持 “地方性”、“应用型”、“本科高校” 这三个关键词, 着重体现办学应用型特点。

目前, 一些地方本科院校的电气信息类专业仍套用以往的学术型大学的办学模式, 继续进行 精英化人才培养, 未能根据地方本科院校的实际情况对办学目标进行精准的定位。比如, 在 专业人才培养方案和课程体系上沿用学术型人才的培养模式, 不注意 “应用型” 技能的培养, 重理论、轻实践, 致使培养出的毕业生在求职过程中找不到适合的工作岗位。而企业在面对 数量庞大的大学生求职队伍时却抱怨找不到所需要的一线应用型人才。通过分析国内电气信 息类专业学生的专业素质和就业现状, 当前毕业大学生的就业能力和用人企业的要求存在的 差异主要表现在:

3.1. 就业观念偏差

我国高等教育已经走向大众化教育阶段, 就业环境和市场已经对于大学生重新定位, 以往的 精英时代的就业观念已经不适应于当前市场需求。我国的电气信息类专业相关企业呈现地区 发展不平衡的特点, 地域的选择已成为影响大学生就业的重要因素之一。但目前大部分地方 院校毕业生的就业观念及其家长的就业期待仍然停留在以往的精英教育时代, 毕业生求职目 标不清、个人期望值过高、不了解行业发展动态, 缺乏自身职业生涯规划等。总之, 一些地 方院校的毕业生的自我定位不符合市场需求, 就业观念存在偏差。

\section{2. 知识结构不合理}

随着科技进步和经济发展的步伐不断加快, 企业对大学生专业知识的要求越来越高。尤其随 着我国工业信息化进程的推进，电气信息类专业知识的较快更新速度使得大学生在课堂上学 
到的理论知识具有滞后性。先进的生产技术在激烈的市场竞争中被企业迅速推广使用, 而部 分院校未能做到与时俱进, 继续采用实施了数十年的课程体系或者照抄学术型大学的培养方 案, 致使以培养面向生产一线的应用型人才为目标的应用型院校的毕业大学生的知识结构与 就业市场需求发生脱节，从而制约了学生就业和专业的发展。

3.3. 实践能力不足

电气信息类应用型人才作为面向电子设备和信息系统相关领域的生产一线工程技术人才, 工 程实践能力是必备的重要技能, 也是培养创新能力的基础。用人单位非常看重应聘者快速适 应工作岗位的实践能力, 每个企业都希望毕业生能 “召之即来, 来之即用”。但目前受当前 我国高校培养方式所限, 一些地方院校未能真正做到应用型人才的培养目标, 毕业生的实践 能力亟待增强。

3. 4. 创新能力不足

在科技飞跃发展的新时代, 企业在谋求立足的同时更谋求发展, 因此用人单位越来越渴求创 新型人才。创新能力已经成为影响大学生就业和个人职业发展一个重要因素, 创新型员工已 经成为企业在激烈的市场竞争中获胜的重要砝码。然而一些地方院校的毕业生由于知识结构、 实践能力和培养方式的限制，创新能力明显不足。

\section{4. 深化校企合作、提升电气信息类应用型人才的就业能力}

校企合作是一种以行业为依托、以就业为导向, 注重在校学习与企业实践, 注重学校与企业 资源共享，与企业零距离接轨的应用型人才培养的企业、学校、学生三赢的合作模式。目前 一些地方本科院校开展的校企合作中, 大部分校企合作模式还停留在一个浅层次阶段, 如大 部分高校采取的是学生到企业进行一般性的见习和实习的方式。而在该模式下，学生与企业 真正的接触较少，未能达到良好的效果；少部分学校通过校企双方共建校内校外生产性实训 基地、“订单式” 培养、定向委培或联合开发项目等方式。虽然该模式下学生与企业接触较 多, 但存在能参与的学生数目有限、实践不灵活等问题。为了提升电气信息类应用型人才的 就业能力, 大力开展深度校企合作模式, 真正实现以行业为依托、以就业为导向、与企业零 距离接轨的人才培养就要学校和企业灵活的利用互补资源、多渠道、深层次开展合作, 确保 电气信息类应用型人才培养目标得以实现。

4. 1. 采用 “全程型” 职业生涯规划指导

大学生职业生涯规划课程对大学生职业发展具有人生导航作用, 针对当前大学生就业观念偏 差问题, 应用型电气信息类专业要充分发挥职业生涯规划课程的作用, 引导毕业生树立正确 的就业观念。目前, 很多高校把职业生涯规划和就业指导课程安排大四上学期, 并且多是采 用辅导员进行授课，由于缺乏全程性和专业性的指导使得职业生涯教育和就业指导无法达到 预期效果，学生职业规划意识模糊，职业目标不明确。电气信息类专业知识更新速度较快， 因此应用型电气信息类专业应从大学一年级就开始、并在四年中分别开设一系列大学生职业 规划方面的课程, 即 “全程型” 职业规划课程, 每一阶段课时分配不必过多, 采用企业技术 人员和专业教师组合的方式授课, 各取所长, 精心设计职业生涯规划课程的实施方案, 及时 引入当前专业发展状况和就业形势内容, 分层次、分阶段有针对性的对学生进行就业指导, 让学生通过在不同阶段的指导, 掌握行业信息、市场需求、发展前景和岗位技能要求等, 结 合自身职业性格进行自我剖析、自我定位, 增强学生学习动力, 避免理想性、功利性和盲目 性的择业倾向, 解决毕业生就业观念偏差问题。

4.2. 构建 “应用型” 人才培养的课程体系

应用型电气信息类人才的培养应以学校与企业的产学研合作为基础, 构建 “应用型” 人才培 养的课程体系, 即加强人才培养的针对性, 以企业实际的需要开设课程, 不应照抄学术型大 学人才培养方案, 将一些与应用型人才培养目标相背离、理论性过强的课程剔除, 构建以就 业为导向, 体现基层一线岗位实际需要技能和素质的, 满足技术人才市场和生产一线需求的 课程体系, 这应是应用型电气信息类专业基本的办学特征和人才培养的类型特色, 人才培养 
课程体系应由学校和企业共同确定, 紧紧围绕当前行业发展特点及所需技能进行理论课程和 实践环节的课程设置, 避免重理论、轻实践现象, 解决毕业生知识结构不合理现象, 要真正 把精力集中在人才培养工作上, 在质量和特色上下工夫。有针对性、有特色并且体现用人单 位实际需求技能的人才培养方案, 是提升电气信息类应用型人才就业能力的重要基础。

4. 3. 运用 “整合型” 实践教学培养方式

在当前高校专业实践环节设置上，往往包含各类课程设计、金工实习、电子实习、生产实习、 毕业见习和毕业设计等内容, 虽然实践环节种类较多, 但受到课程安排和学时的限制, 实践 内容往往分配在不同学期的一段时间内, 加上与理论课程考试时间冲突和校企合作的深度不 够等因素制约, 使得实践环节并未取得预期效果, 这也是当前毕业生实践能力缺乏的主要原 因。深度校企合作模式下的电气信息类应用型人才的培养, 应该有针对性的对实践内容和实 践时间进行整合, 即运用 “整合型” 的实践教学培养方式, 并将整合后的实践教学安排在企 业中实施, 以企业实际需求知识和技能为平台的实践形式是调动学生积极性, 确保实践能力 和创新能力的培养的关键。区别于一般高校所采取的三年半在校理论学习, 半年毕业实习的 教学模式, 应用型电气信息类专业为加强学生的实践能力和创新能力, 可对现有实践环节在 内容和时间上进行整合, 采用 “ $3+1$ ” 的人才培养模式, 即三年在校学习, 一年在企业完成实 践实习和毕业设计, 不应拘泥于传统学术型大学培养模式的限制, 只有让学生身临其境地参 与企业生产、顶岗实习并完成毕业设计才是对于实践内容和实践效果的最大保障, 只有学生 的动手能力和创新能力够得到充分锻炼, 才能确保毕业大学生与企业零距离接轨。

\section{5. 结论}

大学生就业能力逐渐成为制约高校毕业生实现就业的重要因素, 是当前形势下应用型电气信 息类专业谋求立足和发展需要迫切解决的问题。针对电气信息类专业学生在求职时所表现出 的就业观念偏差、知识结构不合理以及实践能力、创新能力不足等问题, 高校应合理运用高 校和企业的资源, 开展深度校企合作, 采用 “全程型” 职业生涯规划指导、构建 “应用型” 人才培养的课程体系、运用 “整合型” 实践教学培养方式解决人才培养中存在的主要问题, 提升电气信息类应用型人才的就业能力，从而真正实现企业、学校、学生三赢的局面。

\section{致谢}

黑龙江省教育科学规划课题省青年专项课题（资助号：GBD1213013）。

\section{References}

[1]. Y. C. Li, "Investigation and Research on the employment ability of Undergraduates in the application oriented Universities," China Higher Education Research, vol.8, pp. 67-69, 2010.

[2]. J. X. Zhang, "Analysis on the strategies of improving the students' high quality employment ability under the new situation," Heilongjiang Researches on Higher Education, vol. 3, pp. 84-86, 2014.

[3]. H. Wang and M. L. He," Cultivation of university students' employability based on the perspective of market demand orientation," Logistics Engineering and Management, vol.3, pp. 230-235, 2012.

[4]. H. Y. Wang and X. j. Li, " Research on the cultivation mode of the $3+1$ talents in the electronic information science and technology specialty of the applied undergraduate," Journal of Changchun University,vol.23,pp.1689-1691,2013.

[5]. Z. G. Fang, "Research on the popularization and cultivation mode of the talents for the science and technology innovation of the electric information technology, "Journal of Huaibei Normal University(Natural Science Edition), vol.34,pp.91-93,2013. 